\title{
Cristóbal Colón como puente trasatlántico en el imaginario de Eugenio María de Hostos
}

\author{
por \\ Asela Rodríguez de Laguna \\ Rutgers, the State University of New Jersey-Newark
}

Desde la publicación de La peregrinación de Bayoán (1863) hasta el 1892 la escritura de Eugenio María de Hostos evidencia un especial interés por la figura de Cristóbal Colón. La centralidad del Descubridor, así como su transformación de genio romántico a positivista en el discurso hostosiano pone de relieve las tensiones históricas, politicas e ideológicas de un sujeto puertorriqueño colonial con respecto a su legado histórico-político. Sirve para cuestionar no solo la figura del mismo Colón, sino la conquista, y la situación de los pueblos de las dos Américas en el siglo diecinueve.

Palabras clave: Cristóbal Colón; descubrimiento; discurso; romanticismo; positivismo.

Para la celebración del Cuarto Centenario del Descubrimiento de América, el patriota y escritor puertorriqueño Eugenio María de Hostos (18391903) se encontraba viviendo con su familia en Chile, donde ocupaba la posición de Rector del Liceo Miguel Luis Amunátegui. En un volumen conmemorativo para dicha ocasión, publicado como número extraordinario de Anales de la Universidad, apareció su ensayo, "El carácter de Colón" y en ese mismo año escribió para un certamen patrocinado por el Ateneo de Lima la oda épica, "El Nacimiento del Mundo Nuevo". El espacio crítico dedicado a Cristóbal Colón no se limita a esos dos textos de 1892, sino que se puede rastrear a la década de 1860 y se manifiesta tanto en su discurso novelístico (donde se integra como elemento estructural y temático) como en el periodístico (referencias, reseñas, y artículos) y en el poético (oda épica). 
Los datos más relevantes sobre la vida del Almirante que recoge Hostos, así como sus observaciones, ideas, opiniones, evaluaciones y reseñas de textos relativos a Colón están recopilados en el volumen X de sus Obras completas de 1939, titulado La cuna de América". Bajo el encasillado de "El descubrimiento y el descubridor" se agrupan la "oda épica", los ensayos "El día de América", "América antecolombina", "La salida de Colón", "La estatua de Colón", "Los restos de Colón" y se incluye el ya mencionado ensayo "El carácter de Colón", casi todos escritos entre 1877 y 1892. La novela La peregrinación de Bayoán (1863), el ensayo "La estatua de Colón" (1865) y estos ensayos se inscriben contextualmente en el marco socio histórico, cultural y político anterior a la Guerra Hispanoamericana y contribuyen a la apreciación de la formación libresca e ideológica y del conocimiento de la historia de Hostos anterior a y al filo del Cuarto Centenario. Ayudan también a comprender un discurso transatlántico que se nutre de las complejas relaciones histórico-políticas entre la metrópoli y la colonia.

Hostos, heredero del positivismo francés, discípulo ecléctico del krausismo español, abolicionista e independentista antillano, se aproxima a Colón desde diversas perspectivas. Su escritura lo devela como un avezado lector y meticuloso cronista de todo lo que se publicaba, planeaba y comentaba sobre Colón, los preparativos previos y durante la conmemoración del Cuarto Centenario del Descubrimiento de América. A primera vista su discurso parece plasmar una actitud y un tono de incondicional admiración afectiva y personal, y conforme a sus sentires e ideario, va construyendo un sujeto Colón pragmático y racionalista. Ese mismo discurso, de raigambre y formación eurocentrista, que se centra en las relaciones entre España, las Antillas, la América de Caupolicán y los Estados Unidos se instaura en una postura transatlántica que deja entrever a su vez las huellas ambivalentes, ambiguas y contradictorias de un sujeto criollo educado, que en diálogo con la tradición y su momento histórico intenta y logra inscribir por un lado su «americanidad», además de exhibir una latente oposición al discurso hegemónico. Una relectura de esta producción escritural, por su carácter mediador, delata manifestaciones, silenciamientos u ocultamientos contradictorios con relación a esta figura histórica y su desempeño en el Descubrimiento.

${ }^{1}$ Esta edición conmemorativa fue auspiciada por el gobierno de Puerto Rico y publicada en La Habana en el 1939. 
Hostos y ColÓN: EN LA METRÓPOLI

El interés y la fascinación de Hostos por Colón se remonta a la publicación de su novela, La peregrinación de Bayoán (1863; 1873), escrita en Madrid a los 24 años. Él mismo cuenta cómo durante las noches de primavera se la leía a Juan de Dios de la Rada y Delgado (1827-1901), a quien alude como «poeta-literato muy conocido en España» ${ }^{2}$. Vale destacar que la redacción de la novela de Hostos coincide por poco tiempo con la publicación y representación en Madrid en 1863 de una obra de Rada escrita en 1852, Cristóbal Colón: drama histórico en tres actos y en verso, texto romántico que escenifica a Colón como un intrépido navegante, un «errante y peregrino» y un «desdichado» personaje lleno de esperanza, paciencia, perseverancia y fervor religioso que triunfa «abriendo á la civilización cristiana un nuevo mundo» ${ }^{3}$. Esta relación, desapercibida por la crítica hostosiana, es una huella y eslabón importante en la inserción del Colón de Hostos dentro del panorama de las relaciones literarias entre escritores y amigos españoles y de los territorios de ultramar y representa una primera instancia de distanciamiento y enfrentamiento críticos de Hostos con respecto a la configuración romántica de Colón.

Ambos textos- el de Rada y el de Hostos- se inscriben dentro del romanticismo español. Se conciben y publican en un momento de cierta creciente popularidad por el tema colombino en España, a raíz del éxito de la traducción al español del libro de Washington Irving y de las traducciones que circularon de la novela de James Fenimore Cooper, Mercedes of Castile or the Voyage to Cathay sobre Colón. Esta parcial explosión publicitaria colombina empieza a manifestarse paulatinamente desde la década de 1830 y va aumentando progresivamente según se aproxima el 1892. Entre los textos que circulan o se representan cerca de o durante la estadía de Hostos en España, baste mencionar, por ejemplo, Isabel I: comedia histórica original en un acto (1851) de Ginés de Moscoge; Cristóbal Colón (1851) de Pablo Alonso de Avecilla, La agonía: juguete dramático en un acto, original y en verso (1861) de Luis Mariano de Larra y Wetoret; los poemas de el Duque de Rivas ("Oda a Cristóbal Colón"), Ramón de Campoamor ("Recuerdos de una gran hombre" 1853), Angel Lasso (“Colón y España”, 1859), V. García-Escobar (Romancero de Cristóbal Colón, 1866) y Narciso Campillo (Nuevas Poesías, 1867).

${ }^{2}$ Entre la numerosa obra de Rada y Delgado, sobresalen Viaje de SS.MM. y A.A. por Castilla-León (1860), Mujeres célebres de España y Portugal (1868), La educación de la mujer por la historia(1869), Los Frescos de Goya en la iglesia de San Antonio (1888) y una Bibliografía numismática española.

3 Rada y Delgado, 1863: 6. 
La peregrinación de Bayoán es el primero de los escritos de Hostos que textualiza y exhibe sus tensiones ideológicas, históricas y políticas como sujeto puertorriqueño colonial que cuestiona el legado político que le ha tocado vivir. Su narratología también configura un discurso finisecular alternativo, distante al de muchos de sus contemporáneos en España por cuanto no articula la visión triunfalista del Descubrimiento y critica la conquista y el dominio occidental como agentes de transformación, cambio o tachadura.

Novela de difícil encasillamiento por sus pronunciadas características simbólico-alegóricas y políticas, La peregrinación de Bayoán es un diario-ensayo ficcional de obvio acento autobiográfico y rasgos románticos. La novela es el diario íntimo del puertorriqueño Bayoán, quien marcha a España en busca de «la verdad, amor a la verdad y a la justicia» ${ }^{4}$ con la resolución de enseñarlas, aún a costa del amor. En su travesía recorre las hermanas Antillas y otros territorios americanos hasta llegar a España. Se encuentra a su amigo Guarionex, y se enamora de su hija, Marién, quien muere al final en España. Los nombres corresponden a las Antillas Mayores y apuntan a ese anhelo e ideal de federalismo antillano que tanto soñó Hostos. Además de autoanálisis, el texto es una meditación y un diálogo sobre la situación, el pasado y porvenir de las Antillas y de la América en general. En este texto se hallan huellas de motivos y preocupaciones claves de su ideario, que desarrollará en textos posteriores, pero que en 1863 se encuentran todavía en estado embrionario.

La peregrinación de Bayoán recoge las pasadas relaciones de la metrópoli con sus posesiones, las condiciones económicas y sociales que aquejan las Antillas, la evocación idílica y paradisíaca del pasado indígena, la naturaleza americana en la vertiente caribeña, los temas del amor, misión y deber, así como la dicotomía entre ciudad y pueblo ${ }^{5}$.

La presencia del sujeto Colón en Hostos se estructura en varios niveles. Primero, desde una perspectiva íntima, Hostos comienza a compartir hasta cierto punto la peregrinación y viaje de Colón en su propia existencia de casi perenne exiliado político, anticipando un largo peregrinaje que le llevará a vivir en España, los Estados Unidos, Sur América (Chile, Venezuela, Argentina, Perú, etc.) y en otras Antillas (República Dominicana), sintiéndose muchas veces presente y ausente por su «extranjeridad». El peregrinaje de Colón, como el de Hostos, no responde a una inquietud banal, sino a una llamada para cumplir una misión. Mientras en Colón significó probar la veracidad de su convicción de que

${ }^{4}$ Hostos, 1970: 99.

${ }_{5}^{5}$ Para un análisis semántico de las implicaciones que la isotopía colonización española, España-Europa (ciudad, metrópoli) versus pueblo (el conjunto de las Antillas, América), ver Andrea Pagni, 1992: 579-591. 
viajando por el oeste se llegaría al este; en el puertorriqueño se centró en lucha por la libertad, la verdad, la justicia y en la búsqueda de apoyo y solidaridad para con la causa independentista de Puerto Rico y Cuba. Peregrinar es para Hostos sufrir, recordar, padecer y sobretodo alejarse de seres queridos. En Colón ve el ejemplo máximo del hombre que en su peregrinar para buscar apoyo y probar su verdad tuvo que luchar contra todo tipo de obstáculos para triunfar por su tenacidad, perseverancia y voluntad. La observación de Hostos en el prólogo de la novela de que «El mundo me ha derrotado muchas veces, cuantas veces he intentado hacer bien con mi pluma, con mi palabra, con mis actos, con mi vida. No me he desalentado jamás ${ }^{6}{ }^{6}$ recuerda muy de cerca al Colón de Rada cuando éste señala que «nunca el desmayo al corazón penetra;/ un oculto poder mis pasos guía,/ y mi esperanza sin cesar alienta» ${ }^{77}$, proto-imagen del Colón de Washington Irving, tan popular en el siglo diecinueve. La «extranjeridad», sin embargo, los hermana como sujetos extrañados y subalternos probándose en los círculos de poder y fuera de la patria o lugar de nacimiento.

Más allá de esa analogía afectiva y vivencial de Hostos con Colón, es importante desentrañar cómo Hostos articula la figura de Colón dentro de su escritura ficcional, y qué función pasa a ocupar en su ideario. El personaje Bayoán, al emprender su peregrinaje desde las Antillas hasta España, recorre el viaje de Colón, pero a la inversa. Más que una relación de semejanzas, paralelismos y meros contrastes, podríamos señalar que el truco del viaje a la inversa de Bayoán le sirve a Hostos para inscribirlo como uno de confrontación, oposición o contestatario al viaje primario y sus consecuencias. Esa confrontación se da en los primeros capítulos del texto, particularmente a través de una conversación o diálogo imaginativo que el personaje entabla con aquel que le precediera a él, Colón, donde se cuestiona el legado colonial, aunque tibiamente, para evadir una censura que aún así prohibió la publicación de la segunda edición en 1873.

Aunque la funcionalidad del sujeto Colón y del motivo del viaje a la inversa en La peregrinación de Bayoán esté íntimamente unido a la visión todavía romántica de un Hostos joven, y se enmarque dentro del contexto literario romántico español de moda, este texto puertorriqueño se aparta drásticamente de otros Colones contemporáneos, sobre todo de la versión triunfalista de su maestro y amigo Rada ${ }^{8}$. Cristóbal Colón: Drama histórico en tres actos y en

\footnotetext{
${ }^{6}$ Hostos, 1970: 17.

7 Rada y Delgado, 1863: 2.

${ }^{8}$ Para otros trabajos que analizan aspectos de la relación, Hostos- descubrimiento a la inversa, pero desde otras perspectivas, ver los estudios de Juan Manuel Rivera, 1989. Rosa, 2003. Y las tesis inéditas de Alonso, 1975 y Waltzer, 1976. Ver también Colón Zayas, 1987. Rivera, 1993. Beauchamp, 1995. Alvarez, 1990.
} 
verso, dedicado a Su Majestad la Reina Isabel II, representa escenas de la vida de Colón, su viaje y llegada, entrelazadas a la historia de un intrigante portugués (Sousa), un enredo amoroso entre Don Luis y Doña Leonor, y escenas de aldeanos y marineros para demostrar cómo el Descubrimiento «cerró el período de la edad media, abriendo a la civilización cristiana un nuevo mundo» ${ }^{9}$. Este Colón, burlado por ser extranjero, en medio de un mundo dominado por la pobreza, enfermedades y supersticiones, llega a la Rábida cansado y sediento con su hijo, y con el apoyo de Marchena, y la Reina, inspirado por Dios, vence todo tipo de adversidades para conseguirle a los hijos de España, pueblo de «indomable saña», de «erguida frente» y «de blasón sin sombra ni mancha» una nueva tierra ${ }^{10}$. La novela de Hostos se instaura como un texto contestatario a esos Colones románticos que solo aquilataron primero, las vicisitudes anteriores al viaje y en segundo lugar, el triunfo.

Los sujetos Colón y viaje también le sirven de punto de enlace entre la escritura y la realidad que Hostos-autor y Bayoán-personaje auscultan e intentan apresar, pero críticamente. Colón sirve de puente, particularmente al principio de la novela, para elaborar una serie de relaciones simbólicas distintas que fluctúan entre el pasado, presente y el futuro utópico. Es un eslabón necesario que le permite al escritor examinar las raíces de la nacionalidad, la crítica del modelo europeo (español) de civilización, además de esbozar la construcción del nuevo hombre del proyecto hostosiano. Su novela, género que luego abandonará Hostos, será la que dé inicio a la novelística puertorriqueña, y queda, gracias a él, unida a la tradición en que lo imaginario está vinculado a la historia pasada fundacional y contemporánea del autor.

Cuando Bayoán se reencuentra imaginativamente con Colón, trata de reevocar sus experiencias, «soñar como soñó Colón» pero no para revivir o repetir ritualísticamente sus experiencias sino para cuestionarlas, subvirtiendo así el viaje de descubrimiento a través de un discurso que recoge también las ambivalencias del pensamiento hostosiano en dicho momento con respecto a las consecuencias del 1492. La repetición de la experiencia originaria está mediatizada por otras experiencias y siglos de alteración y cambios. Ese viaje a la inversa (de Puerto Rico a España) constituye un recorrido hacia el pasado (visitar los lugares por los que pasó Colón) y el presente (visitar lo que son ahora esos lugares y llegar a la metrópoli) pero exteriorizado por un discurso dialógico interior, que le permite a Bayoán articular sus aspiraciones y objetivos (buscar la verdad, la justicia) y examinar la relación y situación sociopolítica de las Antillas y España. Cuando Bayoán reflexiona, desdobla su yo y

\footnotetext{
${ }^{9}$ Rada y Delgado, 1863: 6.

10 Ibidem: 64.
} 
su conciencia en voces diferentes. Esas voces que entablan una conversación, por medio de afirmaciones o negaciones, preguntas y respuestas, evaluaciones y opiniones, son las que sostienen estructuralmente el interés dramático e ideológico del texto. Y es a través de ese diálogo que se transmite un discurso contendiente que reta y cuestiona el discurso dominante del momento. El personaje narrador se enfrenta primero a Colón, luego a otros personajes del pasado indígena (Guanacagarí, Guarionex), a las islas, al paisaje, y a Marién.

El cuestionamiento del pasado y presente en La peregrinación de Bayoán intensifica el enfrentamiento entre Bayoán y la historia de las Antillas y esa confrontación lleva a una importante valoración del paisaje antillano, como marca de la otredad antillana. La afirmación y descripción de sus rasgos geográficos típicos en oposición al paisaje que se encontrará en otras ciudades españolas (Cádiz, Madrid) no responde a una intención de recrear meramente el color local, sino que en la afirmación del paisaje distinto al «otro» (al español), Hostos, como primero Colón, y luego otros que «inventaron» el Nuevo Mundo en el Siglo XIX (Irving, Humbolt) descubre su paisaje antillano. Pero es un paisaje cuya descripción se dá mediatizada por lo que se conoce ya de ese paisaje por los que le precedieron, y lo captaron.

Colón es el primero que describió la geografía americana. Por eso la nueva visión de las Antillas de Bayoán (siglo XIX) tiene en consideración la descrita por Colón. El discurso que enuncia ese paisaje termina por emitir una desarticulación de las visiones primigenias de las Antillas. El paisaje es y no es el mismo, y ausente de él están, sobretodo, los habitantes originales. De ahí que el diario de Bayoán empiece el 12 de octubre, fecha que celebra la culminación de Colón, fecha símbolo de su triunfo, que representa el comienzo de la historia occidental de esas islas y pueblos. En la reescritura de esa segunda descripción (la de las Antillas en el siglo XIX) la primera participa como subtexto pero para señalar ahora lo no existente, lo irrecuperable. Esa actitud nostálgica y melancólica ante la pérdida del pasado precolombino resulta así más desgarradora. En ese diálogo con el paisaje, Bayoán incorpora a su vez una visión que capta el cambio, la transformación habida (característica del progreso), donde lo originario es irrecuperable. Se evoca a Colón, y al paisaje no solo para identificarse parcialmente con ellos, sino para denunciar los estragos del Descubrimiento, como se ve en el siguiente fragmento:

Los mismos contratiempos que al cruzar estas aguas Colón [identificación]; pero no los mismos encantos [la diferencia]; salían a recibirlo de las playas millares de canoas; en ellas, millares de semblantes, [lo interpretado] animados por la confianza y la veneración y por la timidez, de que sólo la hospitalidad sabía vencer [idealización de los habitantes]. 
¿Quién sale ahora de esta costa solitaria? [lo que no existe, los ausentes en el Siglo XIX] La tristeza que agobia al corazón al pensar en el sarcástico progreso, en los irrisorios beneficios que trajo a estos países la cultura de Europa [denuncia de las consecuencias de la civilización]. Colón se entrega a sus ensueños, al son de los instrumentos de los indios, que acompañaban tristemente cantinelas, y dejaba vagar su pensamiento, embriagado por los perfumes de la brisa. [Colón absorto y ensimismado, disfrutando su triunfo versus la tristeza de los aborígenes]

La brisa perfumada, embriaga todavía: no deleita el oído voz alguna: ¡silencio y soledad en todas partes! ${ }^{11}$.

El pasado rememorado y la realidad presente se enuncian en el discurso como deseos y experiencias frustradas: «He querido visitar la Vega Real, el Cibao, cuantos lugares vieron a Colón, cuantos recintos conservan el recuerdo de los sencillos habitantes, y no he podido hacerlo porque ni hay caminos practicables, ni quien conmigo se atreva a practicarlos $\rangle^{12}$.

El procedimiento de anhelar y desear una identificación con los sentimientos de Colón, seguido de una instancia de reconocimiento de lo ausente para pasar inmediatamente a una visión crítica de la contemporaneidad se repite varias veces en el texto. Cuando Bayoán pasa por frente de la costa de la isla Guanahaní:

Con la misma ansiedad con que Colón la esperaba, yo la espero: la veo aparecer, y la bendigo. Ella fue la que premió al genio: ella fue la que le dio aquella alegría misteriosa... Ella fue la que oyó la tercera bendición, digna de Dios, salida de los labios de los hombres...; Apareció y creyeron. Pedestal de Colón, yo te saludo ${ }^{13}$.

Ante ese estado contemplativo y reflexivo Bayoán se dirige a Colón, por medio de un imaginario diálogo interrogativo, en un intento de averiguar y saber la verdad primigenia que Colón conoció:

¡Ah, Colón!!... Mi pensamiento vaga por la región de la verdad, y anhela verla: tú, que lo sabes, contéstame: ¿no es cierto que toda tu vida dolorosa, que tu largo martirio, que las tinieblas palpables que envolvían la luz que tú buscabas fueron irresolución de Dios, que obligado por sus leyes fatales a dar al mundo lo que faltaba al mundo, vacilaba, y dudaba en entregar al hombre su obra más perfecta, la que mejor lo revela? ¿No es verdad que tú sentiste,..., el lugar de la inocencia y de la paz? ${ }^{14}$.

\footnotetext{
${ }^{11}$ Hostos, 1970: 69. Los corchetes son nuestros.

12 Ibidem: 53.

13 Ibidem: 136.

14 Ibidem: 137.
} 
Del Colón como «venerable genio», «ojo tenaz» y «sublime peregrino» pasa a la isla-paisaje para con un tono disquisitivo cuestionar a sus nuevos moradores. Colón es el hombre privilegiado que vivenció la inocencia y paz de un mundo intocado por la civilización europea, pero el legado ha sido el triunfo de una civilización de vicios, egoísmos, leyes sociales, e industria. Bayoán critica, recrimina y condena la civilización, el progreso, plasmando una visión binaria de la naturaleza (Mundo Nuevo vs Europa; inocencia, pureza vs maldad, egoísmos; sociedad sin leyes vs civilización; habitantes originales como «raza generosa», «seres sencillos» vs hombres con vicios y codiciosos; paraíso vs sociedad y civilización). La estrategia de la acumulación de preguntas y respuestas procura inquietar y perturbar al lector y se anclan en el texto como ampollas o martilleos:

Lo está por la raza generosa que veneró a Colón? ¿Lo está por los seres sencillos que amaban al hombre, a su patria, a Dios? ¿La habitan los recuerdos de aquel hombre inmenso?...

Si está habitada, yo me tapo los ojos para no saberlo: no quiero ver lo que he visto en todas partes: nada de lo que había, ni virtudes sencillas, ni bondad, ni vicios sin embozo: todo lo que había; virtudes aparentes, embozada maldad, civilización de vicios: egoísmo, es decir, sociedad; codicia, es decir, comercio, agricultura, industria; felonía, es decir, leyes sociales... ${ }^{15}$

Bayoán-héroe de esta inversa peregrinación para buscar la verdad, libertad y justicia y prepararse para ser modelo del nuevo hombre americano positivista ( basado en la virtud, la razón y el orden) éticamente recurre al pasado, a ese mítico inicio de su mundo occidental, no para rehabilitarlo, sino para sacudirlo y entablar un diálogo con ese pasado ido, pero siempre presente en la tradición y en las interpretaciones sobre dichos orígenes. Colón y el descubrimiento de América componen un horizonte histórico distanciado, separado pero necesariamente presente en el horizonte de Bayoán. Cuando Bayoán, desde su instancia presente se acerca al horizonte histórico del Descubrimiento y a Colón a través de paralelismos y relaciones simbólicas de identificación y confrontación, materializa la tensión entre los dos horizontes y se hacen patentes los efectos del pasado, en este caso, del Descubrimiento (la ausencia de aborígenes, el paisaje transformado) en el presente de Bayoán.

Sin embargo en el discurso que plasma ese choque de horizontes se evidencia la conflictividad del sujeto colonizado, que al hablar exhibe sus contradicciones ante la compleja realidad histórica. Por un lado, como bien ha señalado Andrea Pagni, en el campo semántico se condena el descubrimiento

15 Idem. 
y la conquista porque han traído la civilización («me das asco») y el progreso («irrisorios beneficios que trajo a estos países la cultura de Europa»), también es cierto que Bayoán/Hostos cree firmemente que América será la cede o el «lugar predestinado de una civilización futura», una que en vez de propiciar «vicios, egoísmos, es decir sociedad; codicia, es decir, comercio, agricultura, industria; felonía, es decir, leyes sociales» bajo la figura de algún español apasionado, capaz de justicia, equidad y que ansíe la grandeza de estos pueblos traiga la ciencia, las artes, el comercio (que «dejará de ser mezquino»), la agricultura (para «acabar la obra de Dios»), y la industria (que «se admirará de encontrar un lugar donde lo espera») ${ }^{16}$. Dentro de este esquema, se justifica el descubrimiento, se condena el legado español y se anhela/desea el progreso. Bayoán, pues, simultáneamente valoriza y se identifica con Colón, quien como él se lanzó en busca de la verdad, y con los indígenas, que en su momento confrontaron al español («lo que ellos con sus armas, haré yo con mi voz»). Sin embargo, en el largo proceso de civilizar, los más «débiles» se han eliminado. En el siglo XIX lo que Bayóan puede constatar es su ausencia en las Antillas, y de ahí que en su elucubración de una civilización futura no incluya el componente indígena, aspecto del ideario hostosiano que le critica Pagni cuando compara el pensamiento de Hostos con el de Martí con respecto a la América mestiza ${ }^{17}$. Por lo menos para 1863, cuando Hostos escribe este texto, aún el pensador no ha elaborado su conceptualización de la América total.

El viaje de Bayoán, distinto y por razones diferentes a las de Colón, es un viaje que lo ha sumergido «en la tristeza y amargura» ${ }^{18}$. Esa tristeza, y amargura (como resultado de la imposibilidad de reconciliar el pasado con el presente) son motivos que predominan hasta que Bayoán conoce a Marién y se enamoran. Entonces las alusiones y referencias a Colón disminuyen drásticamente para dar paso al desarrollo del tema del amor, y el de la muerte de Marién al final.

El viaje de Bayoán, que es un viaje de redescubrimiento, se inicia el 12 de octubre y termina a fines de un octubre varios años más tarde. Sin embargo, en las apreciaciones y valoraciones de Colón se va observando una tendencia en Bayoán de divorciar a Colón - agente y gestor- de las consecuencias que, por ejemplo, le causan la «tristeza y amargura», apuntando hacia una condenación de aquellos que no comprendieron ni siguieron al genovés («he sido cruel con ese mundo que mi espíritu vio tras de los mares: lo he entregado a

\footnotetext{
16 Pagni, 1992: 586-88.

17 Ibidem: 589.

${ }^{18}$ Hostos, 1970: 69.
} 
hombres que no me han imitado»). Se reincide en la admiración por Colón y en desvincularlo de las consecuencias de ese primer viaje (desaparición de los indios), reservada para sus acompañantes.

Cuando Bayoán llega a Santo Domingo, "Ciudad funesta a América”, «castigada por el tiempo» porque para 1863 ésta ha perdido su independencia y se ha reintegrado a España, la recrimina por haber sido ingrata «con el único que te quería», por haber martirizado y haber lanzado de su puerto como prisionero «al venerable genio, infeliz por ser genio y venerable» ${ }^{19}$. Pero inmediatamente recapacita para introducir una constante en el discurso hostosiano relacionado con Colón- una lucha entre lo bueno-malo de Colón, entre lo malo-bueno de España: «Soy injusto contigo, capital de la Española: no fuiste tú quien arrojó a Colón, fue su propia crueldad» ${ }^{20}$. Para él, Colón señaló el camino, los españoles y demás europeos que siguieron, lo mancillaron.

Colón es el genio que ha tenido la nefasta suerte de haber visto en toda su dimensión las consecuencias de su hazaña, y de haber sido recompensado con la ingratitud. En Colón-genio, según Bayoán-Hostos hay «propensión al martirio, magnánima sonrisa para la ingratitud ${ }^{21}$. La tragedia de este nuevo Prometeo la explica Colón a Bayoán de la siguiente manera:

Es natural-dijiste- que los hombres me atormenten; les he revelado una verdad: es natural que me persigan; he hecho un bien: es natural que me encadenen...Si hubiera cadenas para el alma, mi alma sería la encadenada. Hay momentos en que creo que la injusticia de los hombres es la revelación de la justicia eterna: he sido cruel con ese mundo que mi espíritu vio tras de los mares: lo he entregado a hombres que no me han imitado, que no han sentido al verlo otro deseo, que el deseo de arrancarle sus tesoros, y he sido castigado: la ingratitud ha sido mi castigo ${ }^{22}$.

Pero para Bayoán, España, a la que a veces llama la «infeliz España» también ha pagado su precio:

Si tú la vieras, Colón, tal vez te espantaría el rigor de la justicia. Nación generosa al defenderla, pequeña al combatir la independencia, purga hoy su pasada pequeñez: lo que debió elevarla, la batió; lo que enriquecerla, la hizo miserable; pequeña, lo que estaba llamado a engradecerla... Está, como los niños, vacilando ${ }^{23}$.

Bayoán anticipa un eterno anhelo de los americanos liberales de que España se arrepienta de sus excesos en la conquista y colonización. Anhela un futuro de hermandad utópico y unión iberoamericana.

\footnotetext{
19 Ibidem: 50.

${ }^{20}$ Ibidem: 51.

21 Idem.

${ }^{22}$ Ibidem: 51-52.

${ }^{23}$ Idem.
} 
En su recorrido por la capital, la Vega Real, por Monte Christi, la Isabela, Jaragua, por la costa cubana, y otras islas, Bayoán, entre recuerdo, nostalgia y crítica, continúa rememorando el pasado, reviviendo la trayectoria y el estado emotivo de Colón: "Con tal que sufra algo de lo que sufrió Colón, y al escribir su historia pueda describir las angustias de ese viaje inmortal, ¿qué me importa llegar a Europa sin recursos $\gg{ }^{24}$ ?

Cuestiona los motivos de la empresa, lamenta la ausencia de los indios y celebra la labor de Las Casas: «Si todos, como tú [Las Casas] hubieran ardido en el fuego del amor de la justicia, aún contemplarían mis ojos, individuos de la noble raza que ahora sólo vive en la historia» ${ }^{25}$. Pero Bayoán evita la indignación. Recuerda y perdona a Guacanagarí, recuerda a la infeliz Anacaona, alaba los cayos que Colón llamó «Jardines de la Reina», desea conseguir un medio que lo lleve a la primera isla que vio Colón y trata de imaginar los sentimientos originales de Colón al contemplar el nuevo mundo. Reitera su admiración por su genio y triunfo ante las adversidades:

Yo veo a Colón y reflejado en mi mente el sentimiento que experimentó: veo su cándida admiración, su expansiva alegría, aumentándose con la frondosidad de los bosques, la limpidez del ambiente, la claridad de los ríos, la ... veo su frente desarrugada, brillando con la luz que le da el genio, cuando al fin encuentra lo que tantas convulsiones interiores le ha costado ${ }^{26}$.

En la articulación del sujeto Colón, del amor, del paisaje americano, la evolución y trayectoria de la civilización se observa una polaridad de oposición entre tinieblas/luz que revierte a la concepción ideológica donde dicha antítesis sintetiza la historia de la humanidad. Las sombras y tinieblas representan las fuerzas opresivas, y los obstáculos que el individuo debe vencer, aunque nunca se especifica bien cómo se aplican a los autóctonos. Esta antítesis se repite constantemente en la novela y en textos posteriores de Hostos, aunque a medida que pasan los años, las asociaciones de luz con Dios, amor y verdad como se registran en La peregrinación de Bayoán son cada vez menos frecuentes y comienzan a asociarse, a tono con su familiaridad con el pensamiento krausista y positivo, a la inteligencia, razón, y conciencia. El elemento religioso irá cediendo al positivismo ecléctico de Hostos.

Colón, como en muchos otros escritores y ensayistas del Siglo XIX, le sirve a Hostos de vehículo o plataforma para exponer conflictivamente su interpretación del «Descubrimiento» de América, y emitir un enjuiciamien-

\footnotetext{
24 Ibidem: 53.

25 Ibidem: 63-64.

26 Ibidem: 75-76.
} 
to no sólo del hombre y la nación que lo apoyó sino del rol de España como nación conquistadora y colonizadora. A través de Colón se condenan las «glorias» españolas del pasado, pero también, es importante destacar la dolorosa y valiente visión y reconocimiento de Hostos como un sujeto histórico escindido y consciente a su vez de una tradición histórica-literaria de raíz anti-española, totalmente condenatoria de la participación de España en la colonización, responsable de intelectualmente formar y desformar y de su experiencia personal como sujeto colonial antillano bajo la política tiránica decimonónica de la metrópoli. Como el mismo Hostos ha señalado en el prólogo de La peregrinación de Bayoán: «Raynal, Robertson, de Pradt, Prescott, Irving, Chevalier, me presentaron a América en el momento de la conquista, y maldije al conquistador. Un viaje a mi patria me la presentó dominada, y maldije al dominador. Otro viaje posterior me la presentó tiranizada, y sentí el deseo imperativo de combatir al tirano de mi patria» ${ }^{27}$.

Para Hostos Colón es una figura paradigmática, fiel a su búsqueda, el primer testigo occidental de la inocencia de la América, cuyo descubrimiento concibe como una gesta occidentalizadora o civilizadora, a pesar de las nefastas consecuencias ${ }^{28}$.

\section{COLON EN OTROS TEXTOS HOSTOSIANOS}

El 12 de octubre de 1865, en Madrid, Hostos publicó un artículo, "La estatua de Colon" ${ }^{29}$ donde elabora otra valoración del genovés destacando su formación, su plan de viaje y su significación histórica. Hostos se reafirma en su creencia en el progreso de la historia y la marcha de los pueblos, aunque reconoce que le entristece y conmueve el constatar en dicha historia la lucha del bien y el mal, lo que eslabona «esa cadena eterna de pequeñeces y grandezas, de crímenes y heroísmos, de infamias y virtudes» ${ }^{30}$. Dentro de ese contexto señala que para él no hay existencia más penosa que la de «las inteligencias superiores» ni siglo que merezca más una estatua o monumento que el Siglo XV para España. Primero enumera los sucesos que hacen de dicho

27 Ibidem: 20.

${ }^{28}$ Marcos Reyes Dávila, en "Hostos, llamarada escrituaria”, Hostos: sentido y proyección, sostiene que el descubrimiento no lo ve positivamente como una gesta de occidentalización. Por lo menos en los escritos relacionados a este tema que consideramos, sin embargo, parecen contradecirlo.

${ }^{29}$ Apareció en La Soberanía Nacional y se recopila en Obras Completas. Edición crítica. Cuento. Teatro. Poesía. Ensayos (1992), edición que utilizamos.

30 Ibidem: 202. 
siglo uno glorioso: la reconstrucción nacional, el progreso político, la unidad, riquezas, triunfos y glorias, predominio internacional, la derrota del árabe, el vencimiento de una religión y el haber hallado el complemento del mundo. De todos, destaca como el hecho más singular y culminante el descubrimiento de «Colombia», nombre del que es un enérgico propulsor. A Colón lo ve como un «pobre diablo», un «loco» importante por «sus hechos», que tuvo tres cunas, una que le dio la espalda (Italia), otra que representó sus luchas (España) y otra, que dignificó su obra ( América). Critica el que América no lleve su nombre. Y siguiendo su fuente bibliográfica principal, Historia de los Reyes Católicos don Fernando y doña Isabel de Bernáldez, lo eleva a un genio solo «después de Dios», cuyo desembarco en el nuevo mundo constituyó el «fin de sus afanes» ${ }^{31}$.

También señala Hostos que para él el día 12 de octubre es un «día sagrado» y lamenta que España no haya podido darle forma a dicha celebración. Exhorta a que se le levante una estatua que pueda servir de doble enseñanza para el individuo y el pueblo de modo que ambos puedan aprender de Colón la fortaleza para llegar a un fin y emulen el ser grande como él, pero recomienda que sean más cautos y menos injustos que aquél, emitiendo de ese modo la primera crítica ética-moral directa contra el Almirante.

En "Páginas íntimas" de las Obras completas de Hostos se hallan dos documentos que revelan otras facetas de esa íntima relación admirativa por Colón. En 1877 Hostos parece encontrar en el «viaje» de Colón una metáfora conveniente para sintetizar las aprehensiones humanas ante el hecho de emprender una nueva jornada, una acción única e insustituible, o de comenzar un nuevo mundo. Estas referencias revelan su familiarización con otras fuentes principales sobre Colón.

Pocos días antes de contraer matrimonio con Inda (Belinda Otilia), por ejemplo, le obsequió a ella un ejemplar de la Vida y viajes de Cristóbal Colón de Washington Irving, y en la dedicatoria (7 de julio de 1877) le escribió:

Como Colón, vamos a embarcarnos para un mundo desconocido. Ya se llevan el equipaje, ya se rompen las ataduras materiales que nos ligan al lugar en que hoy estamos y al estado en que ahora hemos vivido... Como Colón, lo desconocido por delante, la oscuridad en medio, la tristeza del pasado allá atrás. Si llegamos a donde queremos, un nuevo mundo de ventura; si no sabemos llegar, un mundo nuevo de infortunios. Colón supo llegar a Guanahaní: amparémonos en su noble vida y aprendamos en ella a llegar al término del viaje. Yo estaré siempre contigo, Inda mía... ${ }^{32}$

\footnotetext{
31 Ibidem: 208-209.

${ }^{32}$ Hostos, 1939, vol. III: 180.
} 
Hostos privilegia aquí el proceso anticipado para llegar o alcanzar una meta, objetivo o proposición, y la invita a prepararse para la nueva vida matrimonial como un viaje a lo desconocido y a ampararse en "su noble vida» para aprender cómo llegar.

Hostos también le regala a Inda un ejemplar en español de la novela de James Fenimore Cooper, Mercedes of Castile or The Voyage to Cathay (1840), que en la década de los cincuenta se difundió en España bajo el título de Cristóbal Colón. Se la dedica escribiéndole: «Para que Inda lea con más fruto el 'Colón' de Fenimore Cooper ${ }^{33}$. En dicha dedicatoria (6 de julio de 1877) expone concisamente su concepción del relato histórico. Le advierte a Inda que el romance de Cooper no es historia porque no tiene el propósito de juzgar los actos de los hombres; su estilo, grave, no es el de la historia, y no busca con minuciosidad y exactitud la verdad de los hechos en que ha de fundar sus juicios. Pero le advierte que tampoco es novela porque la mayor parte de sus hechos no son imaginarios, sino históricos. Le explica que el texto pertenece al género híbrido de la novela histórica, aquel donde se combinan los elementos propios de la historia con los hechos de la novela para hacer más interesante a una figura histórica, más comprensible una época y más patética la narración de un acontecimiento.

Hostos recomienda la novela de Cooper por considerar dicho género un excelente medio para conocer la personalidad de Colón, develar los motivos vitales que le impulsaron y conocer sus luchas y sacrificios para llevar a cabo su empresa. Para él la obra vale por lo que ofrece de biografía, donde los episodios intercalados e imaginativos (los amores entre Luis de Bobadilla y Mercedes Valverde, y el episodio del amor de la india Ozema por don Luis) no tienen tantos méritos como para nublar la vida de Colón. Hostos, sin embargo, acredita a Cooper el haber sabido representar en esos personajes ficticios tres móviles del alma humana: el ardor generoso de la juventud (don Luis), el noble entusiasmo de la mujer por lo bueno (Mercedes) y la influencia virtuosa que el amor bien sentido y bien dominado tiene para el perfeccionamiento del carácter (en el amor entre ellos). Invita a Inda a que se fije en las buenas ideas y los altos pensamientos que se encuentran en la novela, sobretodo en las ideas «exactas» sobre el descubrimiento, emblema del triunfo de la verdad sobre el error dogmático. Espera que pueda «estimar y admirar y bendecir a

33 Ibidem: 177-179. En su libro sobre Hostos, Adelaida Lugo Guernelli se refiere a esta dedicatoria, pero pone en duda que Hostos se refiera al Colón de Cooper porque no tiene una obra titulada de esa manera. La autora desconoce que la versión castellana de Mercedes of Castile de Cooper se tituló Cristóbal Colón. Hostos sí se refiere al Colón de Cooper. Ver Lugo Guernelli, 1970: 172-174. 
Colón» ${ }^{34}$; reitera su concepción del «descubrimiento» como la culminación o triunfo de la búsqueda de la verdad y finaliza advirtiéndole que como lo que va a leer es una traducción del inglés al español, tenga presente que siempre existirá una distancia entre el pensamiento original y el traducido.

El RECLAMO ESCANDINAVO, LOS Estados Unidos, LA APORTACIÓN PRE-COLOMBINA AL ARTE, LOS RESTOS DE COLON EN ESE DISCURSO TRASATLÁNTICO

Los textos posteriores a La peregrinación de Bayoán (1863) y de sus notas a Inda (1877), como por ejemplo, ensayos, reseñas y artículos periodísticos, comparten con éstos una búsqueda y un deseo de seguir examinando la personalidad de Colón y comunicar el entorno histórico. En su ensayística periodística de tema colombino, Hostos favorece un estilo claro, dinámico, a veces, metafórico para revestir un andamiaje de estructuras discursivas expositivasargumentativas, y en menos casos, descriptivo-narrativas. Retórica y estructuras se complementan para enunciar un mensaje que pretende abarcar funciones informativas y didácticas. En algunos, como en "El carácter de Colón" recurre al retrato como instrumento de análisis psicológico, pero formulando siempre una valoración moral. Estos escritos posteriores a La peregrinación de Bayoán también acusan otras influencias. El tímido romántico Hostos de la década de los sesenta y setenta ha dado paso al hombre positivista y krausista. El 12 de octubre es "El día de América" la fecha en "que nació el Nuevo Mundo para la Historia de la Civilización y de la humanidad occidental» ${ }^{35}$. A Colón lo va transformando en un positivista: le confiere un «ojo seguro», una «razón profética». Le hace moverse en un espacio geográfico-temporal donde es el héroe que se ve «en la soledad de la creencia combatida» ${ }^{36}$. Va configurando a un hombre que en soledad combate la ignorancia, que es fiel a una «luz» (la razón/realidad científica) que le guía para comprobar sus ideas. Colón no es ya el intuitivo ni romántico navegante. Es el hombre que debe a su «fé en una verdad científica» el haberse convertido en el descubridor de «dos trascendentales realidades»: la del «diámetro verdadero del planeta» y del «mundo nuevo» que estaba destinado a proclamar tantas novedades, a establecer y mejorar el orden material y « llamado a transformar el orden político y social» ${ }^{37}$.

\footnotetext{
${ }^{34}$ Ibidem: 179.

${ }^{35}$ Hostos, 1939, vol. X: 11.

${ }^{36}$ Idem.

37 Ibidem: 12.
} 
Si para Hostos el descubrimiento fue la culminación que demostró la fuerza de la verdad, su aplicación, también, generó graves diferencias en la vida resultante, observable por ejemplo en la «formación, desarrollo y existencia de las dos grandes porciones que geográfica e históricamente lo constituyen $\rangle^{38}$. Esboza así su interpretación de las diferencias radicales entre las dos Américas, compartiendo con otros, anteriores y contemporáneos, a saber José Martí, el mexicano Justo Sierra y el chileno Francisco Bilbao, su interés por las diferencias de la historia de la América hispana o latina con la anglosajona. Por lo menos en estos textos ("El día de América", "América antecolombina"), distintos a "La América Latina", Hostos promulga una posición admirativa y de absoluta confianza en los ideales y logros de Norteamérica como lo hiciera Lastarria, y critica la tradición hispánica como en su tiempo lo hicieron Echeverria, Bello y otros. En un discurso que se estructura a base de la enumeración de características contrapuestas, impone un cuadro de diferencias u oposiciones, donde siempre sale favorecida la nación anglosajona. Hostos mide el progreso o adelanto no sólo desde ángulos políticos, sino religiosos, sociales e institucionales. Se observa una valoración negativa del resultado de la emancipación al catalogar despectivamente a las naciones emergentes hispanoamericanas como «nacioncitas». En el esquema de Hostos, mientras que el Norte establece una sociedad superior basada la adopción del régimen municipal y regional para su democracia representativa, el «libre examen» y la separación de la iglesia y estado («el orden temporal y espiritual») y la federación como «la unidad nacional más extensa, más vigorosa, mejor articulada del mundo», los países hispanos se han sometido a los errores políticos y administrativos de Europa, a una «contrarevolución religiosa y filosófica, que ni se espantó con la Inquisición» para romper con tres años siglos de coloniaje para fabricar «una porción de nacioncitas sin vigor» ${ }^{39}$. Advierte Hostos que dichas nacioncitas están predestinadas por su origen y «existencia colectiva, a pasar por vicisitudes perturbadoras, antes de encontrar el equilibrio y reposo que en el primer momento malograron $»^{40}$.

En el esquema comparativo del pensador todavía no resalta nada positivo con respecto a las aportaciones del mundo nuevo a la civilización occidental, excepto una «portentosa cantidad de materia poética y estética» al mundo. La Europa puede encontrar, según él, en la ante y post historia del Descubrimiento, en la variedad de razas, en la diversidad de la geografía y en el espíritu del nuevo actor elementos de una lírica descriptiva y subjetiva, épica o

\footnotetext{
38 Idem.

39 Ibidem: 12-13.

40 Ibidem: 13.
} 
dramática social que puede sustituir las «formas viejas» y «estrechos moldes» de la literatura europea decimonónica ${ }^{41}$. Entrevé el mestizaje y la hibridez étnica como marcas del futuro americano cuando señala que el hombre americano (producto de tres grupos primarios: el indígena, el conquistador, y el africano, además del coolie y el chino) espera la voz de un gran poeta que pueda condensar el «sollozo» y el lamentar de esa «humanidad adoptada por América, para producir la lírica más bella, más profunda, más racional y más humana» ${ }^{42}$. Estas observaciones colocan a Hostos en precursor decimonónico de una visión favorable al mestizaje.

Subraya otros beneficios que el descubrimiento ha legado a la humanidad, a saber, el vapor, la electricidad, la aplicación de las ciencias a las artes de la vida y sobretodo dos: el Océano Pacífico y el de la Federación. El Pacífico es símbolo de la vida y apertura hacia el ideal americano (que debe ser la fusión de las razas en una misma civilización) y el segundo, la Federación como expresión «orgánica del símbolo»; como la meta del ideal del Nuevo Mundo: «la unión de todas las naciones» ${ }^{43}$.

$\mathrm{Si}$ en estos textos Hostos examina y ausculta la realidad americana a partir de 1492, una ojeada por sus otros escritos periodísticos lo muestran como un «lector» ávido, crítico y como un agente de difusión y diseminación de libros, noticias e información. Cuando reseña, no se limita sólo a informar, a presentar los caracteres generales de la obra que pretende llevar al público lector, sino que arguye, corrige y cortésmente (a veces) rebate, amplía o ilustra sus observaciones para ofrecer su propia contribución al desarrollo de una idea, o intercala documentos para que hablen por sí mismos. "América antecolombina", "La estatua de Colón" y "Los restos de Colón" pertenecen a esta categoría.

"América antecolombina" es una reseña de la traducción al español del libro del mismo título del escandinavo Carl Rafn, quien intentó reivindicar para su patria la gloria del Descubrimiento de América. Cuidadosamente Hostos reconstruye y explica la tesis escandinava, con pruebas que apoyan su llegada y colonización desde el Siglo X hasta el XIV para proceder entonces a rebatirla. Hostos no niega los hechos pero considera que «No hay modo racional de dar a ese hecho ninguna trascendencia histórica ${ }^{44} \mathrm{y}$ concluye que lo que los escandinavos hicieron «no trasciende al tiempo ni a la Humanidad» ${ }^{45}$. En vir-

\footnotetext{
41 Ibidem: 15.

42 Ibidem: 17.

43 Ibidem: 19.

${ }^{44}$ Ibidem: 35.

45 Ibidem: 36.
} 
tud de su ninguna trascendencia histórica (se reduce a la literatura, las Eddas, la historia, Sagas y geografía, el Landorama) se hace «bien en no reconocer el descubrimiento de América por los escandinavos, porque el verdadero de América es el hecho por Colón» ${ }^{46}$. Para él, cuando los escandinavos logren presentar un argumento que sobrepase la transcendencia alcanzada por el hallazgo de Colón, entonces podrán atribuirse dicho descubrimiento.

Hostos defiende los aportes que el 1492 legó al mundo, a saber: el crecimiento de la población del planeta por el efecto de la alimentación que la América proveyó al mundo (maíz, papa, cacao, azúcar); la formación de más de veinte naciones nuevas; la expansión marítima, comercial, industrial; el aumento de las fuerzas productivas; la transformación de la vida humana (en cuanto a razón, orden, conciencia, libertad); y la transformación del Viejo Mundo en otro y el Nuevo Mundo en otro. Dentro de ese corpus de contribuciones es interesante notar que Hostos destaca el movimiento migratorio como causante de un nuevo fenómeno global-la dilatación de la patria (lugar de nacimiento versus el hogar que se elige) o la distinción entre espacio natal y la ciudadanía adoptada.

Arremete contra aquellos que apocan y disminuyen la obra de Colón, y les invita a que presenten un cuadro más amplio de oportunidades y beneficios que los que se han conseguido por el Descubrimiento, tales como 1) un continente entero que sirva de asilo a millones de europeos; 2) una organización política basada en la igualdad de todos los derechos, conciencias, soberanías; 3) la igualdad jurídica dotando al mundo de la fuerza de iniciativa individual; 4) la igualdad de conciencias produciendo la fuerza armonizada de las religiones como una de las bases del orden social; 5) la igualdad de soberanías, desarrollando la fuerza de la iniciativa colectiva; 6) una humanidad completa, íntegra y fuerte como la que en el centro del Continente septentrional se ha puesto a vivir racionalmente, desentendiéndose de los desvíos de la razón que tanto han atrasado el desarrollo de las otras sociedades; 7) un pueblo que sólo en un siglo haya hecho lo que han hecho los Estados Unidos y 8) que presenten una historia tan original como la del Nuevo Mundo en la que «no sólo es original el abandono de los hijos de ingleses a los dictados de la razón práctica, sino la lucha de los hijos latinos por romper el molde en que nacieron y viven encerrados $\gg{ }^{47}$.

Para Hostos, sin Colón no habría Nuevo Mundo, ni nueva humanidad y ni tampoco una nueva civilización. Para él:

\footnotetext{
46 Idem.

47 Ibidem: 38-39.
} 
fuera lo que fuera, un aventurero, un loco, un ignorante, fué un gran hombre. Pero no grande hombre como los que nacen en cualquier momento de la Historia, sino de los que nacen en momento oportuno, imprimen a la Historia un nuevo movimiento, porque son hombres completos; hombres de errores, de pasiones, de flaquezas; pero hombres completos como él era; sensibilidad de primera magnitud, carácter de primer orden: entendimiento soberano ${ }^{48}$.

Lejos queda el espacio antillano privilegiado en La peregrinación de Bayoán. Hostos habla por y para todo el continente americano. Pero, su pensamiento racionalista y positivista lo obligan a aliarse con el único modelo que considera racional y exitoso, el de los Estados Unidos. América como locus utópico del futuro para una nueva civilización es una aspiración repetitiva deseada y mientras, el único experimento que ha triunfado es el de los Estados Unidos, la otra América sigue luchando por liberarse de esa «Europa», en este caso, España.

"La salida de Colón" exhibe ecos muy cercanos a la novela de Cooper, particularmente en la descripción de las actitudes del pueblo al filo de la partida. Hostos selecciona aquí el momento anterior a la salida del puerto de Palos en 1492. Comienza sintetizando los logros marítimos de los portugueses, la colonización de las Islas Canarias a partir de 1405 para enmarcar esos procesos como avances necesarios en la erradicación del miedo con respecto al desconocido mar. Hostos va tejiendo una narrativa colombina, apoyada en una atmósfera que contrasta ese clima propiciatorio de revelaciones con los temores, miedos y recelos del pueblo común. En esa escala ascendente de descubrimientos, no sobresale nadie como Colón, a quien define como un visionario y como un loco con más razón que todos los cuerdos de su tiempo. Es un hombre «fijo en su idea, firme en su voluntad, tranquilo en su conciencia, modesto en su dignidad, solemne en su diligencia» y hábil negociante ${ }^{49}$.

La participación de los hermanos Pinzón (en lo que Hostos sigue a Humbolt, Irving y a Cooper), importante por lo que aportaron- una nave, capital para tripularla y abastecerla, tripulantes y la habilidad psicológica para aplacar la resistencia y el temor del pueblo- es también objeto de condena. Ellos son los responsables de comercializar y deslucir la empresa por su deslealtad y envidia por «arrebatar a Colón, el extranjero, los méritos históricos que se quieren atribuir a Pinzón» ${ }^{50}$. En su motivación y participación no encuentra Hostos «ningún alto motivo, ni el patriotismo, ni el espíritu religioso ni espíritu monárquico», pues los movió «la esperanza de beneficios pecuniarios,

\footnotetext{
48 Idem.

49 Ibidem: 44, 46.

s0 Ibidem: 47.
} 
la codicia, y al más responsable de los tres, Martín Alonso, lo movieron la codicia, la envidia y la ambición» ${ }^{51}$. Entraron como «comerciantes atraídos por una proposición ventajosa» ${ }^{52}$, e hicieron que América naciera «entre vagidos de dolor» y no de alegría. Con esta caracterización culmina Hostos una interpretación del descubrimiento que, aunque ya había advertido en el prólogo de La peregrinación de Bayoán estaba moldeada por lecturas extranjeras anti españolas, ahora se asumen como certeras: Colón es el genial agente noble que señala el espacio utópico y los españoles, los destructores de la inocencia y del paraíso utópico.

En "A dónde iban" Hostos caracteriza al Almirante como «la más poderosa intelectualidad científica de todo el siglo», el más «instruído» de los navegantes de su época, el «descubridor de un mundo imaginado», sólo indicado por Estrabón y por Séneca que terminó siendo «el hombre veraz, el buscador de la verdad, el creyente de la verdad, que sin más guía que ella, sufrió toda su vida por mostrarla, la mostró sufriendo...» ${ }^{53}$. Excusa todos sus posibles «defectos de carácter» como defectos del fuerte porque dan «fuerza a la luz de un gran caracter» ${ }^{54}$. Reconoce que no fue «un santo» ni «humilde» ni «contentadizo», pero lo disculpa porque en todas las instancias donde se ponía en tela de juicio su integridad, Colón sólo reaccionaba ante la situación, o porque le agotaban la paciencia o conspiraban contra él. No adulaba ni asaltaba a los que lo criticaban y prefería romper negociaciones a ceder los honores y mercedes que pedía. Lo considera «desinteresado» porque sólo pedía la décima parte de los tesoros y un octavo más de los beneficios si costeaba parte de los gastos. Para Hostos, si era irascible, era porque arremetía "contra la indignidad que lo acechaba»; si era duro, era para señalar el abuso de la nacionalidad sobre la extranjería; si no era humilde, era para mostrar desdén y si era codicioso, se debía a que era un padre virtuoso que deseaba salvar a us hijos de la indigencia. Además de excusarlo, Hostos intenta siempre reconciliar las representaciones negativas de un Colón irascible, duro, codicioso con la de un Colón soñador (buscaba el rescate de Jerusalén) y la del Colón víctima (por la suspicacia del poder) que muere en la miseria ${ }^{55}$.

Para Hostos, el pensador moral por excelencia, la virtuosidad de Colón sólo amerita condenación "cuando lo veo derramar sangre de indígenas», cuando inaugura «la cacería horrenda que desplomó el primer descubrimien-

\footnotetext{
51 Ibidem: 48.

52 Ibidem: 49.

53 Ibidem: 61, 63, 65.

54 Ibidem: 67.

55 Ibidem: 70 .
} 
to, y ser ingrato, injusto y cruel con aquellos deudores representantes de la barbarie inofensiva e inocente a quienes la Historia y la civilización le habrán agradecido tanto que hubiese civilizado en vez de empezado a destruir» ${ }^{56}$. Inexcusables para Hostos son la mortífera conquista y la temperancia con el régimen de la esclavitud. Por lo demás, afirma, que Colón (dotado de conciencia y razón) fue clemente (a Roldán perdona dos veces), firme, constante $\mathrm{y}$ de fe en la verdad.

En otros artículos, como en "La estatua de Colón" Hostos se muestra no sólo un gran conocedor de la escultura y de la pintura, sino un teórico que analiza las dificultades que un artista confronta al intentar expresar la magnitud de un tema como el del descubrimiento o de Colón. Adscribiéndose a una concepción idealista del arte, Hostos parte de que para interpretar a Colón «tal como fué Colón, es afearlo, porque es empequeñecerlo» ${ }^{57}$. Para él «ser Colón es haber sido, después de Sócrates, de Jesús, acaso de Confucio, el más impersonal que pueda caber de la forzosa personalidad de carne y hueso. Haber sido impersonal es haber sido todo hombre, nada hombrecillo; todo humanidad, nada individualidad; todo concentración de la especie en uno, nada expansión del individuo en todos a costa de todos» ${ }^{58}$. Y luego añade «haber sido Colón es haber sido trabajo, pensamiento, esfuerzo, sacrificio, caridad, virtud; es haber sido lo más alto que se puede ser, lo único que vale la molestia de vivir: una conciencia» ${ }^{59}$. Porque la finalidad de la conciencia es el conocimiento del ser y sus medios «Haber sido conciencia es haber sido incapaz de ponerse al nivel de los hombres negativos» ${ }^{60}$.

$\mathrm{Ni}$ en este ensayo ni en otros posteriores aludirá Hostos a los ataques fundamentales que en esta misma época se divulgaban en contra del carácter y comportamiento de Colón, a saber su relación extra matrimonial con Beatriz, sus problemas administrativos en la Hispaniola, su incapacidad para gobernar y otros. Para Hostos el Colón que vale es el hombre hasta 1492, el que prueba lo que necesitaba demostrar como «perseverante descubridor de una verdad» ${ }^{61}$, y de ahí en adelante, el hombre que es objeto de la ingratitud humana.

En "Los restos de Colón" Hostos relata la historia sus restos y la de sus familiares. Describe vívidamente la exhumación en Santo Domingo y transcribe documentos de algunos de los dignatarios políticos y diplomáticos de

\footnotetext{
56 Ibidem: 71.

57 Ibidem: 107.

58 Ibidem: 106.

59 Idem.

${ }^{60}$ Idem.

${ }^{61}$ Ibidem: 114.
} 
España e Italia que presenciaron la urna donde yacía el «gran mártir de la ingratitud humana ${ }^{62}$. Revela dos fuentes más que maneja sobre Colón, la obra del norteamericano Harrise, autor también de un ensayo titulado Los restos de Cristóbal Colón y el texto de Rodolfo Cronau, América, historia del descubrimiento desde los tiempos primitivos hasta los modernos. Obra dedicada a solemnizar el cuarto centenario del descubrimiento de América por Cristóbal Colón (1892), que lee en versión castellana que circuló en ese mismo año.

\section{Últimos ESCRITOS SOBRE COLON}

Dos escritos importantes, por haber sido redactados para las efemérides del Cuarto Centenario, "El carácter de Colón" y la oda épica "El nacimiento del Mundo Nuevo" son sus testimonios finales sobre Colón. Hostos, que además de los apologistas colombinos conocía también a sus detractores, los redacta en Chile, como señalamos al principio. En el primero se muestra un poco más distanciado del «gran mártir de la ingratitud». Hay elogio del «gran varón» pero el mismo va precedido de una enumeración de las debilidades de su carácter, que por su extensión, ocupan más espacio que sus virtudes. Además, a pesar de que la figura central continúa siendo Colón, Hostos le dedica espacio a otras personalidades que en la larga trayectoria del Almirante le sirvieron de ayudantes o agentes positivos y pro activos ( Juan Pérez de Marchena, Diego Deza, Beatriz) o representaron obstáculos (el arzobispo de Granada Talavera, Fonseca, Fernando el Católico). Es un ensayo menos personal y apasionado, en el que predomina el análisis psicológico, social y moral de la personalidad del genovés. A Colón se le construye más como un ente enteramente de gran voluntad, que por medio de unas cuantas intuiciones fabrica un ideal, cimentado en la verdad, y que aspira a un bien ${ }^{63}$.

Para Hostos lo positivamente grande en el carácter de Colón es la «universalidad de ajentes morales que en él actúan» y su fecundidad ${ }^{64}$. Lo primero que señala es que a Colón siempre se le trata como a persona de distinción, trato que nunca pidió, pero que desde Juan II de Portugal, el cardenal Pedro González de Mendoza (quien lo recibe como 'príncipe') hasta los reyes, se le dio. Se le recibió de modo solemne, sin que Colón se abrogara dicho trato.

62 Ibidem: 156.

${ }^{63}$ Utilizamos aquí la edición original que apareció en Anales de la Universidad (Santiago de Chile), número publicado para conmemorar el 12 de octubre de 1892. Ver Hostos, 1982: 259.

${ }^{64}$ Ibidem: 240. 
De sus debilidades, resalta varias: que en algunos momentos no se acordó de sus amigos Marchena, ni de Diego Deza y sí en exceso de aquellos que necesitaba, la Reina Isabel y otros; que fue codicioso, y egoísta cuando le dice al Rey que en esas tierras que nadie «trate ni faga pié estranjero» ${ }^{65}$; que pensó mucho en el oro; que se mostró muy natural al apoderarse de algunos indios para llevarlos a España y que fue ingenuo al hablar del derecho de los Reyes de Castilla a la persona, las creencias y la vida de los indígenas demostrando «una pequeñez de miras que lo pondrían al nivel de los conquistadores inescrupulosos que malograron tanto para la civilización cuanto bien lograron con el Descubrimiento para España» ${ }^{66}$; que en la catástrofe de la Navidad empezó a revelar una cierta falta de justicia, que fue madre de su crueldad o de su falta de piedad para con los indígenas. Para el puertorriqueño éstos resultan, tal vez, lo más imperdonable de su carácter.

Pero esas debilidades se originan de acuerdo a Hostos en la sensibilidad tan viva, abundante y multiforme de Colón, que son formas morbosas, pero debilidades en fin de su carácter. Son ellas las responsables de que hiciera «concesiones cualesquiera, aunque odiosas, con tal de dar a las tierras descubiertas el valor comercial y la significación mística que había de valerle el reconocimiento de sus servicios» ${ }^{67}$.

Para Hostos, un hombre como Colón se prueba en la hora del testamento. Colón, moribundo sabe expresar (1) arrepentimiento, como, por ejemplo, por Beatriz; (2) afecto por los suyos, por quienes pidió y luchó en las capitulaciones, exigiendo títulos e instituyendo su sucesión, y (3) conciencia, al pedir misas por él, por la que fue su mujer y sus descendientes.

Como hombre de familia fue ejemplar. Con el primogénito fue padre y madre a la vez; al segundo le proporcionó una educación y les dejó instrucciones para que se trataran como hermanos. Fue un apasionado de sus hermanos. Para Hostos, Colón odiaba porque amaba, pero borraba del alma el odio. Sobretodo Colón era voluntad para lograr su fin. Resumiendo, para Hostos la grandeza de Colón podría sintetizarse cuando él dice:

Fué tan fecundo, porque a la variedad estraordinaria de episodios que, dentro del mismo drama o movimiento de vida, se ofrecieron, correspondió con igual variedad de afectos i de esfuerzos. Fué tan poderoso, porque la fuerza de resistencia que acumuló en la incesante serie de contrariedades que formaron su voluntad, era la necesaria para el objeto de su vida ${ }^{68}$.

\footnotetext{
${ }^{65}$ Ibidem: 241.

66 Ibidem: 242.

${ }^{67}$ Idem.

${ }^{68}$ Ibidem: 254.
} 
Hostos, cuya poesía es escasa, compone una oda épica que no posee más valor que el de constituir uno de los pocos poemas épicos escritos en español sobre Colón en el amplio contexto iberoamericano puesto que los textos más conocidos, The Columbiad (1807) de Joel Barlow, Colón (1854) de Ramón de Campoamor y La Atlántida (1877) de Jacinto Verdaguer son poemas extensos ${ }^{69}$. Tampoco tiene "El nacimiento del Mundo Nuevo" el vigor, finura poética, agilidad de movimiento, sencillez de la expresión, musicalidad ni imágenes vivas que se encuentran en otros poetas modernistas que también se interesaron en Colón, como Whitman, Amado Nervo, Rubén Darío. El poema de Hostos, con su pesado y rígido molde de silvas y de versos endecasílabos, octosílabos y algunos heptasílabos, en un lenguaje arcaico, se centra en la grave tensión generada por la complejidad del «nacimiento»y articulación de un mundo nuevo, que da fruto a otro nuevo. En ese alumbramiento, doloroso como todos, Colón es el genio, el «visionario obstinado», el símbolo de la razón y agente que cierra una etapa (la Edad Media) para abrir otra, que «lleno de indecisión, cogitabundo» asiste a la «muerte de un mundo» y a la aparición de «otro mundo». Colón es único testigo de la belleza y pureza del «Edén», sus Adanes y una Eva. Pero ese primer encuentro, concebido como un pacto en que los «hijos de América adoraron/ Y los hijos de Europa/ Benevolencia y gratitud expresaron ${ }^{70}$, se malogra por los compañeros de Colón, descritos como esa turba anonadada, impía, «del labio duro y corazón inerte/ del caucásico fuerte» ${ }^{71}$ que convulsan el alma de la única Eva.

La oda, de unos 308 versos, concluye la visión y triunfo de Colón cuando destaca el surgimiento de una estatua animada, síntesis de la imagen pictórica popularizada de Colón donde éste toma posesión del «pedestal eterno», mira, alza la mano, levanta la cabeza altivamente, y domina la tierra y mar en medio de una turba que se arrodilla y otro grupo, representando la raza subyugada, la víctima inmolada, o la inocente gente, que le contempla. El tono cambia y la voz poética se hace ligera, irónica y crítica, particularmente por medio del constante contraste entre turba-inocentes Adanes y Eva, turba impía/ gente pía como símbolos, una «del mal que engendra el bien» y la otra, «del bien que

${ }^{69}$ Este poema se escribió con la intención de participar en un certamen convocado por el Ateneo de Lima en Santiago. Se incluyó en la edición de Obras completas (1939), bajo el título de "El Nacimiento del Nuevo Mundo". Para un estudio del original, con sugerencias del poeta y amigo de Hostos, Guillermo Matta, ver Vivian Quiles Calderín, "Un poema de Hostos revisado por Guillermo Matta". Utilizamos aquí la nueva versión, la original, publicada en Obras completas, edición crítica. Cuento. Teatro. Poesía. Ensayo, 1992. Ver Hostos, 1992.

70 Ibidem: 188.

${ }^{71}$ Idem. 
aborta al mal» ${ }^{72}$. El título alude al doloroso comienzo, pero se detiene proporcionalmente más en poetizar al Colón sufrido por causa de la envidia, la calumnia, la injusticia, la crueldad, la codicia y la turba inconsciente, que en las «víctimas sacrificadas». El mundo nuevo lo asocia al espacio en que el hombre nuevo (Colón) podrá implementar «el nuevo ideal, no un nuevo mundo/ Sino un mundo nuevo, original, ungido/Por el combate y el dolor le entrega ${ }^{73} \mathrm{de}$ esperanza, sentido común, libertad, lo bello y el bien. Su mundo nuevo es un espacio utópico, y la forma que asume es la épica, el molde para la construcción de una figura de tránsito entre una época y otra, engrandecida por la magnitud de su hazaña- comprobar su verdad-, pero empañada por la desaparición de otros.

Con este texto Hostos culmina un discurso que marca claramente su identificación con los valores decimonónicos de progreso y civilización. Las consecuencias las dejaría para otros textos y poemas como "Los conquistadores de Chile".

Colón, en la concepción del puertorriqueño, como en la de otros escritores y pensadores hispanoamericanos de su época no se distancian de la pintura que de él hicieron Prescott, Irving o Cooper. Su hazaña no la desvirtúa él, sino aquellos que le siguieron, y sus defectos, defectos del ser humano, son excusables ante la grandeza del hombre genio que se dedica a buscar la verdad, aunque sea un hombre tan distante y opuesto moralmente a la conducta del autor y al «hombre completo» que Hostos postulara en sus tratados de moral. La figura de Colón desaparece casi totalmente de la escritura hostosiana a partir de 1892 como a partir de la Guerra Hispanoamericana de1898 disminuyen sus enjuiciamientos admirativos del «Norte».

\section{BiBLIOGRAFÍA}

Abellán, José Luis, "La dimensión krausa-positivista en Eugenio María de Hostos", Cuadernos Americanos, III/16 (Ciudad de México, 1989): 58-66.

Alonso, Luis Ricardo, "Hostos y Martí: novelistas", Tesis doctoral, Boston College, 1975.

Alvarez, Ernesto, "Hostos y Colón, Vidas Paralelas", Revista de Estudios Generales, IV/4 (Río Piedras, P. R., julio 1989-julio 1990): 13-42.

Beauchamp, José B., "La construcción de la cotidianidad, la historia y el ensayo en La peregrinación de Bayoán", Julio César López (ed.), Hostos: sentido y proyección de su obra en América, Río Piedras, Universidad de Puerto Rico/Instituto de Estudios Hostosianos, 1995: 521-540.

\footnotetext{
72 Ibidem: 192.

${ }^{73}$ Ibidem: 192-193.
} 
Caballero Wangüemert, María, Memoria, escritura, identidad nacional: Eugenio María de Hostos, Murcia, Cuadernos de América sin nombre, 12, 2005.

Colón Zayas, Eliseo R., "La escritura ante la formación de la conciencia nacional: La peregrinación de Bayoán de Eugenio María de Hostos", Revista Iberoamericana, XLIII/140 (Pittsburgh, Jul.-sept. 1987): 627-634.

Córdoba Iturregui, Felix, "Hostos y la Ilustración”, La Torre, V (Río Piedras, P. R., 1991): 157- 168.

Hostos, Eugenio Carlos de (ed.), Hostos, hispanoamericanista, Madrid, Juan Bravo, 1962.

Hostos, Eugenio María de, "El carácter de Colón”, Anales de la Universidad de Chile, Número estraordinario pub. para la celebración del cuarto centenario del descubrimiento de América, 12 de octubre de 1892, Santiago, Imprenta Cervantes, 1892: 239-260.

Hostos, Eugenio María de, Obras completas, 20 vols, La Habana, Cultural S.A., 1939, vol. III: $177-180$ y vol. X: 1-165.

Hostos, Eugenio María de, La peregrinación de Bayoán, San Juan, Instituto de Cultura Puertorriqueña, 1970. Serie Biblioteca Popular.

Hostos, Eugenio María de, Obra literaria selecta, selección, prólogo, cronología y bibliografía, Julio César López, Caracas, Biblioteca Ayacucho, 1988.

Hostos, Eugenio María de, Obras completas. Edición crítica. Cuento. Teatro. Poesía. Ensayo, ed. revisada y anotada por Marcos Reyes Dávila, Vivian Quiles Calderín y Julio C. López, San Juan, Editorial del Instituto de Cultura Puertorriqueña y de la Universidad de Puerto Rico, 1992: 201-210.

López, Julio César (ed.), Hostos: sentido y proyección de su obra en América, Río Piedras, Universidad de Puerto Rico/Instituto de Estudios Hostosianos, 1995.

Lugo Guernelli, Adelaida, Eugenio María de Hostos, Ensayista y crítico literario, San Juan, Instituto de Cultura Puertorriqueña, 1970.

Maldonado-Denis, Manuel: La visión de Eugenio María de Hostos sobre el descubrimiento, la conquista y la colonización de América, Río Piedras, Universidad de Puerto Rico/Comisión Puertorriqueña para la Celebración del Quinto Centenario del Descubrimiento de América y Puerto Rico, 1992.

Pagni, Andrea, "Las contradicciones en el discurso independentista de Eugenio María de Hostos: Una aproximación a La peregrinación de Bayoán (1863)", Titus Heydenreich (ed.), Columbus Zwischen Zwei Welter: Historische und literarische Wertungen aus funf Jahrhunderten, Frankfurt, Vervuert, 1992: 579-591.

Quiles Calderín, Vivian, "Un poema de Hostos revisado por Guillermo Matta", $B a$ yoán, Boletín trimestral del Comité del sesquicentenario de Hostos, I/2 (Río Piedras, P. R., 1987): 33- 35. 
Rada y Delgado, Juan de Dios de la, Cristóbal Colón: drama histórico en tres actos y en verso, Madrid, Imprenta de José Rodríguez Factor, 1863.

Reyes Dávila, Marcos, “Hostos, llamarada escrituaria”, Julio César López (ed.), Hostos: sentido y proyección de su obra en América, Río Piedras, Instituto de Estudios Hostosianos/Universidad de Puerto Rico, 1995: 553-566.

Rivera, Angel A., "La peregrinación de Bayoán, de Eugenio María de Hostos: viaje de retorno al caos", Revista Canadiense de Estudios Hispánicos, XVII/3 (Toronto, primavera 1993): 525-535.

Rivera, Juan Manuel, "La peregrinación de Bayoán: Fragmentos de una lectura disidente”, Revista de Crítica Literaria Latinoamericana V/5, 30 (Lima, 1989): 39-55.

Rosa, Richard, Los fantasmas de la razón. Una lectura material de Hostos, San Juan, Santo Domingo, Isla Negra, 2003.

Villanueva-Collado, Alfredo, "Eugenio María de Hostos ante un conflicto modernismo/modernista", Revista Iberoamericana, 59/162-163 (Pittsburgh, Jan.-June 1993): 21-32.

Waltzer, Hildreth N. "The Inner Pilgrimage of Eugenio María de Hostos, As Seen Through Bayoán”, Tesis doctoral, New York University, 1976.

Fecha de recepción: 10 de junio de 2013.

Fecha de envío de las modificaciones: 5 de febrero de 2014.

Fecha de aceptación: 10 de febrero de 2014.

\section{Christopher Columbus as a trasatlantic bridge in the literary imaginary of Eugenio María de Hostos}

Since Eugenio María de Hostos' publication in 1863 of La peregrinación de Bayoán until 1892, Columbus occupies a central space in his writings. The transformation of Columbus from a Romantic to a Positivist hero serves to exhibit the ideological, historical and political tensions of a colonial Puerto Rican subject questioning his historical and political legacy. It also triggers the examination not only of the figure of Columbus, Spain and the conquest, but of the Nineteenth century complex reality of the American, Caribbean and Latin American nation states.

Key words: Christopher Columbus; Discovery; discourse; Romanticism; Positivism. 